\title{
CHEWING GUM CONTAINING PROPOLIS WAX FROM APIS MELLIFERA BEES FOR PREVENTION OF DENTAL CARIES DISEASE
}

\author{
SRI ANGKY SOEKANTO ${ }^{1,3 *}$, ASTRID LEVINA ${ }^{1}$, EKA NURIN SHARFINA IRIANTO², ACHMAD HUDA FAUZI ADZIMA ${ }^{2}$, \\ HERI HERMANSYAH ${ }^{2}$, ANONDHO WIJANARKO ${ }^{2}$, MUHAMAD SAHLAN ${ }^{2,3}$
}

${ }^{1}$ Department of Oral Biology, Faculty of Dentistry, Universitas Indonesia, Jakarta, Indonesia. ${ }^{2}$ Department of Chemical Engineering, Faculty of Engineering, Universitas Indonesia, Depok, Indonesia. ${ }^{3}$ Research Center for Biomedical Engineering, Faculty of Engineering, Universitas Indonesia, Depok, Indonesia. Email: sriangky@ui.ac.id

Received 11 September 2018, Revised and Accepted 15 December 2018

\section{ABSTRACT}

Objective: Dental caries is caused by demineralization of the tooth surface by organic acids as a result of metabolism of cariogenic bacteria, especially Streptococcus mutans. Chewing gum has been proven to help prevent dental caries formation by stimulating salivary flow and thus reducing the availability of nutrients for cariogenic bacteria.

Methods: In this study, sugar-free chewing gum was formulated using latex from the jelutong tree (Dyera costuata) with the addition of propolis wax $(1-5 \%)$ as an antibacterial agent to inhibit the activity of S. mutans and prevent biofilm formation, which is an early disease stage of dental caries. Characterization of jelutong latex using differential scanning calorimetry and thermogravimetric analysis shows that the latex has glass transition temperatures of $-22.46^{\circ} \mathrm{C}$ and $33.86^{\circ} \mathrm{C}$, and it contains volatile (14.96\%), polymer (84.43\%), organic (0.36\%), and inorganic $(0.25 \%)$ components. The propolis wax used in this formulation mostly contains resin and wax and is a purification by-product of raw propolis obtained from Apis mellifera.

Results: Flavonoids acting as antibacterial compounds are found in propolis, and presumably are also found in propolis wax; thus, probably this compound also has the antibacterial properties of propolis. The in vitro testing showed that $5 \%$ propolis wax in sugar-free chewing gum can prevent the formation of dental caries by inhibiting biofilm formation with up to $80 \%$ more effectiveness relative to negative controls (without chewing gum).

Conclusion: Propolis wax chewing gum can inhibit the formation of dental caries disease.

Keywords: Biofilm, Chewing gum, Formulation Streptococcus mutans, Wax propolis.

(C) 2019 The Authors. Published by Innovare Academic Sciences Pvt Ltd. This is an open access article under the CC BY license (http://creativecommons. org/licenses/by/4. 0/) DOI: http://dx.doi.org/10.22159/ijap.2019.v11s1.15941

\section{INTRODUCTION}

Dental caries is caused by the activity of microorganisms in the oral cavity and affects dental hard tissue, i.e., enamel, dentin, and cementum. To date, caries continues to be a health problem in both developed and developing countries. According to data from Riset Kesehatan Dasar (Rikesdas) conducted by the Ministry of Health in 2013, the prevalence of oral and dental problems in Indonesia is approaching $43.3 \%$ [1]. Caries, also generally known as cavities or tooth decay, are unfortunately commonly considered as unimportant and not lifethreatening. Prevention of dental caries development is important because these can cause focal infections of dental origin, i.e. chronic infections in a location that can leads to the triggering of disease or infections in other organs such as the lungs, heart, or brain, which can potentially lead to death.

The main cause of dental caries is Streptococcus mutans [2], which produces acid from dietary sugars that attach to tooth surfaces forming dental plaque. These acids dissolve tooth enamel and cause demineralization, and the erosion of calcium and phosphate layers on the tooth surface leads to dental caries. To prevent dental caries, the growth of cariogenic bacteria in the oral cavity must be inhibited, especially that of $S$. mutans. Chewing gum has been shown to be a stimulation activity of salivary flow helping in reducing food residues in the oral cavity, thereby reducing nutrients for cariogenic bacterial population [3]. Therefore, sugar-free chewing gum is often used as an anticaries dental product.

Utilization of natural ingredients as antibacterial substances is already commonplace, and one of these is bee propolis. For humans, propolis is very beneficial for health because it contains flavonoids, phenolic derivative compounds, and aromatic acids, which acts as an antioxidant and antibacterial compound. Raw bee propolis must be purified before further processing and utilization. A by-product of the refining process is propolis wax, which until now has not been used further due to its low polyphenol content (approximately 2.4-5\%). However, at these levels, the polyphenols in propolis wax are still considered as effective for inhibition of the activity of S. mutans, i.e., propolis wax which leads to $100 \%$ inhibition of $S$. mutans when used at a concentration of $45 \mathrm{mg} / \mathrm{ml}$ [4].

Thus, in this study, sugar-free chewing gum was formulated with the addition of propolis wax as an active antibacterial agent. The formulations were tested for their ability to inhibit the activity of S. mutans in vitro and to determine the effectiveness of the wax in the prevention of the formation of dental plaque-forming primary colonies.

\section{METHODS}

Materials

The inorganic materials required included the following: Presto cooker $\left(\right.$ Maxim $^{\circledR}$ ), incubator (Memmert ${ }^{\circledR}$, Japan), $0.22 \mu \mathrm{m}$ filters and syringes (Sartorius Minisart ${ }^{\circledR}$, Germany), vortex (SciQuip, England), $1.5 \mathrm{~mL}$ microcentrifuge tubes, micropipettes (ExtraGene, Germany), 24-well plates, Petri dishes (TPP, Switzerland), cell scrapers (Iwaki ${ }^{\circledR}$, Japan), loops, autoclave (Nacro e series model 9000-D, Germany), and aluminum container for the manufacturing of chewing gum, mortar for chewing simulation, and glassware for analysis (Pyrex ${ }^{\circledR}$, Japan).

Organic materials included: Jelutong latex (Dyera costulata; from North Sumatra), Arabic gum, Apis mellifera beeswax and propolis 
wax, glycerine, oleum menthae, forest honey (from North Sumatra), sugarleaf Stevia, demineralized water (provided by Brataco, Indonesia), phosphate-buffered saline (PBS), brain heart infusion (BHI) broth and agar (provided by Sigma Aldrich), and S. mutans strain ATCC 25175.

\section{Manufacturing of chewing gum}

Chewing gum was made in five variations of propolis wax concentrations (1-5\%) with one piece as a blank; the mass compositions of all the gums are listed in Table 1. All formulas were prepared with the same methodology and operating conditions. The manufacturing process was done through repeated heating using a Presto cooker and by mixing the ingredients in the following order: Jelutong latex - Beeswax - Gum arabic - Glycerine - Honey - Stevia and then add propolis wax as mentioned above. Each chewing gum formulation was served in a mass of $3 \mathrm{~g}$.

\section{Antibacterial activity tests}

As a first step in sample preparation, pure human saliva was collected in centrifuge tubes. The collected saliva was centrifuged for $20 \mathrm{~min}$ at $4500 \times$ g at $4^{\circ} \mathrm{C}$. Saliva was diluted $\times 10$ with sterile PBS and filtered using a $0.22 \mu \mathrm{m}$ syringe filter (Merck Millipore, USA). Tests were performed by simulating the process of chewing gum using a mortar with a grinding rate of 1 rotation/s and a salivary flow rate of $0.7 \mathrm{~mL} / \mathrm{min}$.

The following step involved producing the culture media (BHI agar), preparing the bacterial stock, and sterilizing the necessary tools through autoclaving at $121^{\circ} \mathrm{C}$ for $2 \mathrm{~h}$. S. mutans stock was made by inoculating 1 loop of pure culture into $5 \mathrm{ml}$ of BHI broth followed by incubation at $37^{\circ} \mathrm{C}$ for $24 \mathrm{~h}$. The stock was diluted using BHI broth to a concentration of $10^{6} \mathrm{CFU} / \mathrm{mL}$.

About $250 \mathrm{~L}$ of each test sample (a mixture of saliva and chewing gum) was placed into each well in a 24-well plate and incubated for $90 \mathrm{~min}$ at $37^{\circ} \mathrm{C}$. Then, each well was washed with $500 \mathrm{~L}$ of sterile PBS, followed by inoculation of $1000 \mu \mathrm{L}$ S. mutans culture into each well and incubation for 24 or $48 \mathrm{~h}$. The supernatant and biofilm formed on the bottom of each well were then inoculated on BHI agar by a spread plate method. The number of colonies formed was calculated using the total plate count method.

\section{Characteristics of jelutong latex (D. costulata)}

In formulating this gum, jelutong latex (D. costulata) was selected as the elastomer mixture of the gum base, as it is a natural elastomer used in chewing gums and has been approved by the Food and Drug Administration, USA. The thermal profile of the latex is obtained by analyzing the transition temperature ( $\mathrm{Tg}$ ) using differential scanning calorimetry (DSC, ASTM D3418-08), while the latex composition was determined through analysis of thermal resistance by thermogravimetric analysis (TGA; ASTM E1131-08).

DSC analysis was performed to determine the glass $\mathrm{Tg}$ of the latex. It was done with a heating rate of $30^{\circ} \mathrm{C} / \mathrm{min}$, with nitrogen as a purge gas at a flow rate of $20 \mathrm{~mL} / \mathrm{min}$. The analysis was performed with a heatingcooling-heating temperature program $\left(50^{\circ} \mathrm{C}-140^{\circ} \mathrm{C}-\left[-100^{\circ} \mathrm{C}\right]-100^{\circ} \mathrm{C}\right)$.

\section{RESULTS}

The first and second endothermic peaks at $-22.46^{\circ} \mathrm{C}$ and $33.86^{\circ} \mathrm{C}$ indicate the $\mathrm{Tg}$ points of jelutong latex, below or above which the

Table 1: Mass composition of gum lump

\begin{tabular}{lll}
\hline Materials & Function & \% mass \\
\hline Jelutong latex & Elastomer & 30.5 \\
Beeswax & Emulsifier & 5.1 \\
Gum arabic & Plasticizer & 19.4 \\
Glycerine & Softener & 9.3 \\
Oleum menthae & Mint flavor & 3.0 \\
Honey & Sweetener & 12.0 \\
Stevia & Sweetener (polyols) & 20.7 \\
\hline
\end{tabular}

polymer will be glassy or rubbery, respectively. Glass transition occurs due to the rise of temperature of amorphous solids and appears as a step in the basic recording of the DSC signal. This occurs due to a change in the heat capacity of the sample; however, no formal phase change occurs. With increasing temperature, an amorphous solid becomes less viscous or melts.

The TGA thermogram of jelutong latex showed a significant decrease in mass at temperatures of approximately $200^{\circ} \mathrm{C}, 300^{\circ} \mathrm{C}$, and $700^{\circ} \mathrm{C}$, which is most likely due to the loss of volatile elements, polymer chains, and carbon, respectively. From these data, it can be concluded that jelutong latex is composed of the following components: Volatile $(14.96 \%)$, polymer $(84.43 \%)$, organic $(0.36 \%)$, and inorganic $(0.25 \%)$.

\section{Evaluation of physical characteristics of chewing gum}

In the early stages of producing gum base, jelutong latex was first heated to soften its texture for \pm 20 - 30 min using a Presto cooker to speed up the process. After the latex softened, it was rinsed with sterile water to dissolve impurities. This process was repeated until the runoff water was no longer cloudy. After cleansing the latex of impurities, the manufacturing of the gum base mixture softened the latex back into a suitable consistency for the mixing process. The first ingredient mixed with the softened latex was beeswax, resulting in a slightly elastic mixture due to the nature of the beeswax, which has a high plasticity at a relatively low temperature $\left(\sim 32^{\circ} \mathrm{C}\right)$. Next, after forming a homogeneous mixture, the mixture was heated to soften it again; this step made the mixture much easier to mix. With such a consistency, all the remaining ingredients (gum arabic, glycerin, sweetener, and flavoring agent) were added to the mixture and stirred to form a homogeneous mixture. As a result of this mixing, a very elastic gum was formed due to the presence of a plasticizer (beeswax), softener (glycerin), and emulsifier (gum arabic).

Gum arabic is a product commonly used as a component of chewing gum to enable all the ingredients to blend together and form an emulsion. Gum arabic is produced from the sap (resin) of various species of Acasia. Its commercial form is a water-soluble white powder. Gum arabic contains a combination of D-galactose, L-arabinose, D-galacturonic acid, and L-rhamnose. Gum arabic contains arabinogalactan protein and glycoprotein (GP) acting as an emulsifier and thickener, respectively. Gum arabic is an effective emulsifier for thickening due to its ability to protect colloids. It has unique properties of high solubility and low viscosity. However, gum arabic is slowly degraded, thereby reducing the efficiency of emulsification. Thus, the heating temperature must be controlled to reduce heating time [5].

Honey was used as a natural sweetener at the beginning of the manufacturing process. This selection was based on the assumption that the viscosity of honey is enough to produce a homogeneous mixture within a chewing gum formulation. In practice, to achieve a good-tasting chewing gum, honey is required in large quantities, but due to its hydrophobic nature, it was incapable of forming a homogeneous mixture with the elastomers used in this study. Therefore, stevia was used in combination for sweetening; the use of stevia without the combination of honey was considered less suitable due to Stevia's bitter taste. Thus, in our formulation, honey and stevia were combined as sweeteners to create a homogenous mixture and appropriate flavor.

The flavoring agent used in this chewing gum formulation is peppermint oil, which is a volatile compound extracted through a steam distillation process of fresh stems and leaves of Mentha haplocalyx Briq. The usage of original peppermint extract as a flavouring agent in the chewing gum is for the safety in this formulation. The addition of propolis wax and flavoring agents within chewing gum formulation is performed last, after all heating has been completed to maintain the quality of the active compounds in propolis wax, as well as to maintain the peppermint taste, as the latter is a volatile compound (Fig. 1). 

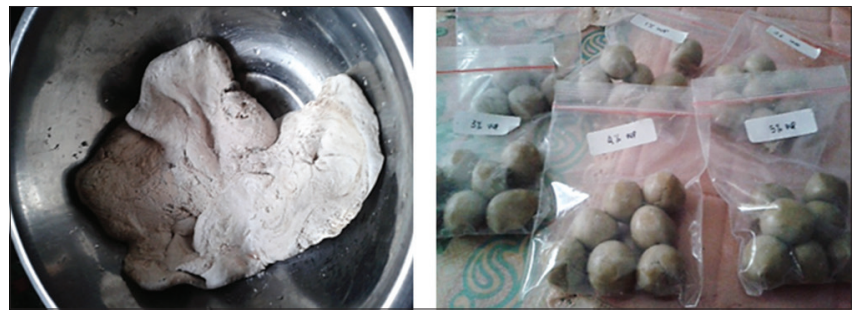

Fig. 1: Formulation results. Left: Gum base; Right: Propolis wax chewing gum

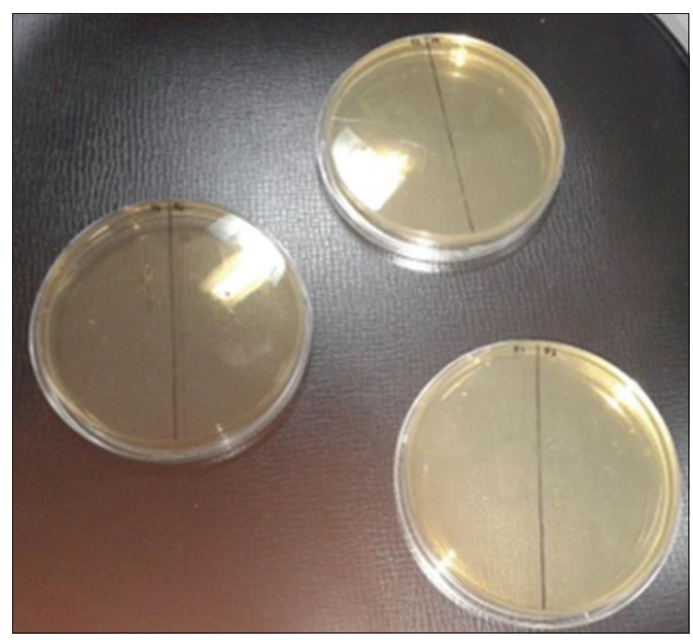

Fig. 2: Sample solution in brain heart infusion medium

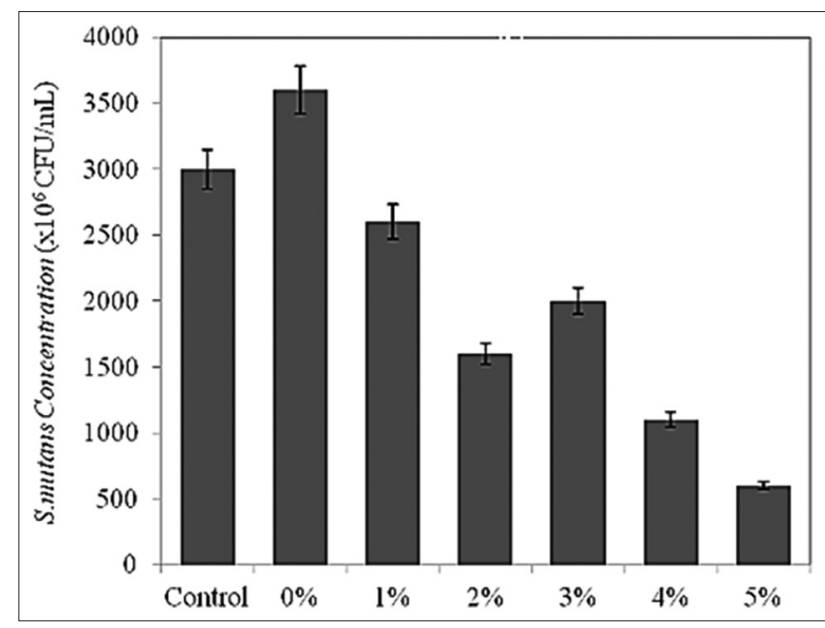

Fig. 3: Relationship between the concentration of propolis wax and concentration of Streptococcus mutans in biofilm layer

Antibacterial activity test of propolis wax chewing gum

The antibacterial activity of propolis wax chewing gum can be examined based on its ability to inhibit the growth of a cariogenic bacterium, $S$. mutans, in vitro. This test was performed by simulating the formation of dental biofilms on a well plate. The sample used was a model of human saliva having consumed propolis chewing gum; this model was prepared by grinding the gum in sterile saliva for $20 \mathrm{~min}$ using a mortar simulating the mechanical movement occurring in the human oral cavity while chewing a gum. The solutions obtained after grinding were then used as a pellicle-forming layer in a well plate. To ensure that the sample solutions were free of contaminants, each solution was inoculated on BHI Agar. As seen in Fig. 2, there were no bacterial colonies formed on agar for any sample, so indicating that the solution was free of contaminants.
A sterile sample then inoculated onto a well plate and incubated for $90 \mathrm{~min}$ at $37^{\circ} \mathrm{C}$. During the incubation process, GP from saliva (mucin) precipitates and forms a thin layer coating the bottom surface of the well plate, termed as pellicle. This exactly simulates the human oral cavity, wherein the bond between the adsorption and desorption of salivary molecules occurs $90-120$ min after brushing the teeth [6]. In this period, a pellicle is formed and works like a two-sided adhesive, with one side attached to the tooth, while the other attaches bacteria [7].

After the pellicle was formed, $10^{6} \mathrm{CFU} / \mathrm{mL}$ S. mutans were inoculated into each well in a high-caries activity model. S. mutans attached to the pellicle layer at the bottom of each well through adhesion, a specific molecule on the bacterial surface. S. mutans has various cell surface polymers acting as antigens, such as antigen B, I/II, IF, Pac, SR, and P1, which act as adhesins interacting with the receptors in the dental pellicle. The interaction between the bacteria and saliva forms a biofilm layer on tooth surfaces, initiating a colonization process. S. mutans can bind and aggregate with various salivary molecules, such as sIgA, B2, microglobulin, histidine-rich polypeptides, GP $60 \mathrm{kDa}$, and GPs with high molecular weight. Especially for the Pac antigen, it is known that it can bind to salivary proteins with a molecular weight of $28,000 \mathrm{kDa}$, lysozyme, and $\alpha$-amylase. Salivary proteins that bind to the Pac molecule are known as salivary agglutinin and serve as a medium for S. mutans adhesion.

To estimate the number of bacteria in biofilms and planktonic form, biofilm and supernatant samples from each well were inoculated on BHI agar plates using the spread plate method. To simplify the calculation of colonies, each biofilm and supernatant sample was diluted $\times 6$ using $\mathrm{BHI}$ broth before inoculating on the plate. The number of colonies formed on each plate was calculated and then multiplied by the dilution factor to obtain the number of bacteria present in each well. The result of the calculation is mentioned in Tables 2 and 3 . When the data were subjected to ANOVA, it was found that the growth of $S$. mutans was significantly affected by propolis wax $(\mathrm{p}<0.05)$.

\section{DISCUSSION}

Effect of propolis wax concentration in chewing gum on antibacterial activity

The relationship between the concentration of propolis wax and cariogenic bacterial activity is shown in Tables 2 and 3 .

As shown in Table 2 and Fig. 3, in in vitro conditions, the higher the propolis wax concentration in chewing gum, the higher is the inhibition of biofilm formation.

Propolis wax contains polyphenols at concentrations of approximately 2.4-5\%, and the presence of these polyphenol compounds indicates that it retains antibacterial activity, just as propolis [4]. This is confirmed by the decreased number of $S$. mutans colonies in biofilm associated with the increased percentage of propolis wax in chewing gum.

Based on previous studies, polyphenol compounds play a role in the inhibition of $S$. mutans growth by inhibiting the synthesis of glucuronyl transferase (GTF) enzyme. In S. mutans, GTF plays a role in extracellular synthesis of glucan, a high molecular weight polymer, which aids in the aggregation of bacteria through interaction with glucan-binding proteins. S. mutans produces three types of GTFs, namely GTF B (synthesizing the insoluble $\alpha$-1,3-glucan), GTF C (synthesizing a mixture of $\alpha$-1,3-glucan and $\alpha$-1,6-glucan), and GTF D (synthesizing the insoluble $\alpha$-1,6-glucan) [8].

In in situ conditions, sucrose derived from carbohydrates will be acted on by GTF B and GTF C to form insoluble glucans, whereas the GTF D produces soluble glucans acting as a primer for GTF B to catalyze polysaccharide synthesis. Furthermore, the glucan molecules will bind to each other, forming a matrix aiding S. mutans adhesion (attachment phase) and assisting in its accumulation (maturity phase) in the pellicle layer. 
Table 2: Total number of colonies formed in $24 \mathrm{~h}$

\begin{tabular}{|c|c|c|}
\hline $\begin{array}{l}\text { Propolis wax } \\
\text { concentration (\%) }\end{array}$ & $\begin{array}{l}\text { Biofilm } \\
\left(\times 10^{6} \mathrm{CFU} / \mathrm{mL}\right)\end{array}$ & $\begin{array}{l}\text { Planktonic } \\
\left(\times 10^{6} \mathrm{CFU} / \mathrm{mL}\right)\end{array}$ \\
\hline Control (saliva) & 3000 & 1900 \\
\hline 0 (blank) & 3600 & 1100 \\
\hline 1 & 2600 & 2000 \\
\hline 2 & 1600 & 2500 \\
\hline 3 & 2000 & 2000 \\
\hline 4 & 1100 & 2400 \\
\hline 5 & 600 & 3500 \\
\hline
\end{tabular}

Table 3: Total number of colonies formed in $48 \mathrm{~h}$

\begin{tabular}{|c|c|c|}
\hline $\begin{array}{l}\text { Propolis wax } \\
\text { concentration (\%) }\end{array}$ & $\begin{array}{l}\text { Biofilm } \\
\left(\times 10^{6} \mathrm{CFU} / \mathrm{mL}\right)\end{array}$ & $\begin{array}{l}\text { Planktonic } \\
\left(\times 10^{6} \mathrm{CFU} / \mathrm{mL}\right)\end{array}$ \\
\hline Control (saliva) & 3500 & 1500 \\
\hline 0 (blank) & 4000 & 900 \\
\hline 1 & 2800 & 1700 \\
\hline 2 & 1100 & 3000 \\
\hline 3 & 1700 & 2300 \\
\hline 4 & 700 & 2700 \\
\hline 5 & 400 & 3700 \\
\hline
\end{tabular}

Table 4: Effectiveness of propolis wax chewing gum in biofilm inhibition. Percentage of inhibition after $24 \mathrm{~h}$ relative to controls; percentage inhibition after $48 \mathrm{~h}$ relative to the number of colonies at $24 \mathrm{~h}$ of treatment

\begin{tabular}{lll}
\hline Propolis wax concentration (\%) & \multicolumn{2}{l}{$\mathbf{\%}$ inhibition } \\
\cline { 2 - 3 } & $\mathbf{2 4} \mathbf{h}$ & $\mathbf{4 8} \mathbf{h}$ \\
\hline 0 & -20 & -11 \\
1 & 13 & -8 \\
2 & 47 & 31 \\
3 & 33 & 15 \\
4 & 63 & 36 \\
5 & 80 & 33 \\
\hline
\end{tabular}

Propolis wax chewing gum consumption causes the dispersion of active compounds in propolis wax within saliva so that the pellicle layer is dominated by the active compounds. Considering that propolis wax is a by-product of raw propolis purification, which still contains $13-15 \%$ propolis resin, it can be assumed that the antibacterial agents in propolis are also contained in the propolis wax.

Flavonoids are the polyphenol compounds showing the most active antibacterial properties: Flavones and flavonols as effective GTF inhibitors and flavanones and dihydroflavonol pinobanksin-3-acetate as antibacterial agents. Until now, the exact mechanism of flavonoids acting to inhibit GTF activity by $S$. mutans is unknown. However, as per previous studies, GTF enzyme inhibition depends on the molecular structure of flavonoids and physical condition of the enzyme itself. Flavones and flavonols, which have unsaturated double bonds between positions $\mathrm{C}-2$ and $\mathrm{C}-3$, showed a remarkable inhibition of GTF activity; conversely, flavanones and dihydroflavonol, which do not have a double bond between $\mathrm{C}-2$ and $\mathrm{C}-3$, showed modest inhibitory activity [8]. The presence of a double bond between C-2 and C-3 provides a site for a nucleophilic addition reaction by side chains of amino acids on the GTF. The amino acid playing an important role in this reaction is aspartic acid, as the aspartic acid side chain $\left(\mathrm{CH}_{2} \mathrm{COOH}\right)$ acts as a nucleophile reacting with flavones and flavonols and inhibiting the activity of GTF. This GTF inhibition can inhibit the adhesion of $S$. mutans on well surfaces due to a reduced hydrophobicity of the bacterial surface; consequently, biofilm formation is inhibited.
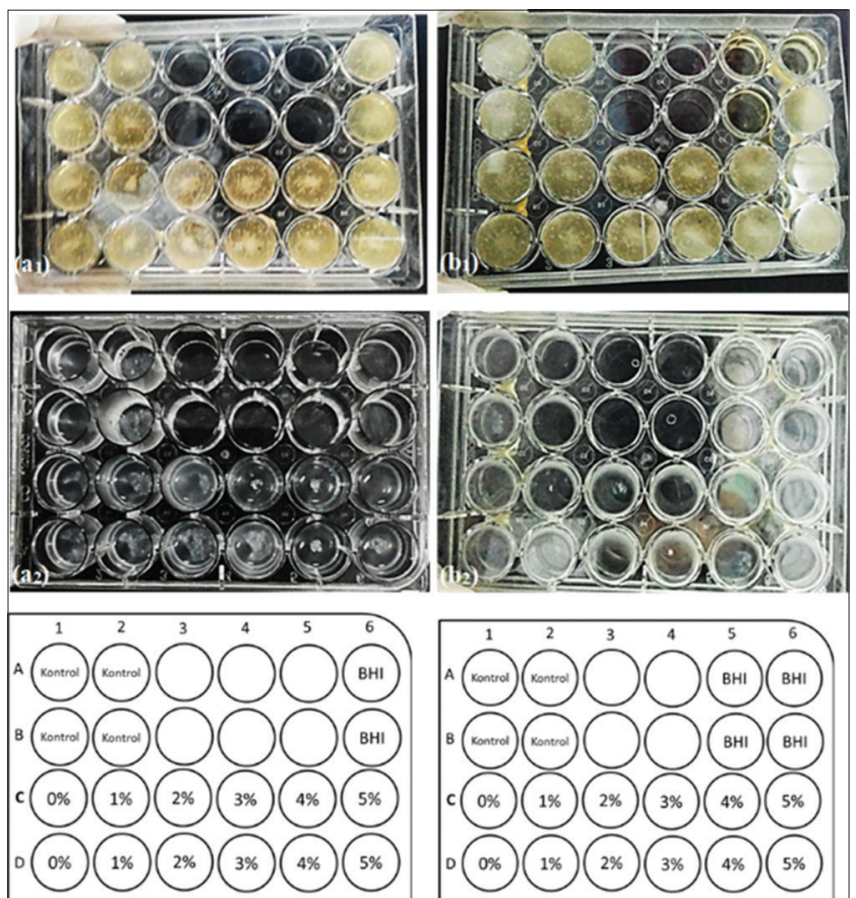

Fig. 4: Results of bacteria culture in well plates. $\left(a_{1}\right)$ The results of 24-h incubation; $\left(a_{2}\right)$ the results after 24-h incubation and washing with sterile phosphate buffered saline (PBS); ( $\left.b_{1}\right)$ the results after 48-h incubation; $\left(a_{2}\right)$ the results after $48-h$ incubation and washing with sterile PBS

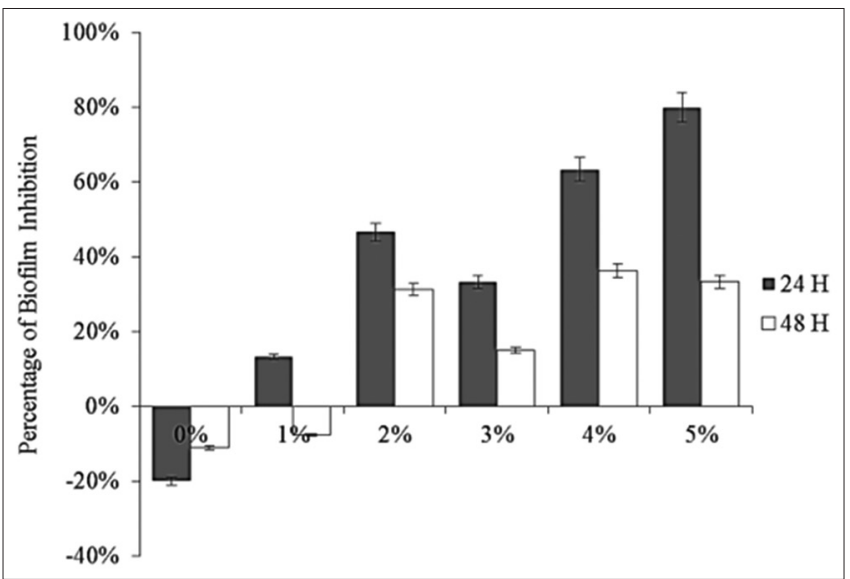

Fig. 5: Relationship of times against the effectiveness of biofilm inhibition

Effect of time on the antibacterial activity of propolis wax chewing gum

Time was one of the modified variables in this study observing the performance of the active compound propolis wax in the inhibition of cariogenic bacteria in forming biofilms. After incubation for $24 \mathrm{~h}$, it can be seen qualitatively that there are two types of colonies formed in the well plate, the planktonic bacteria in the supernatant and the bacterial colonies forming a biofilm layer at the base of the wells (Fig. 4).

In the first row of Fig. 4, it is shown that the supernatants after $48 \mathrm{~h}$ of incubation are relatively cloudier than the supernatants after $24 \mathrm{~h}$ of incubation, meaning that the supernatants contain more $S$. mutans in a planktonic form. In the second row, it can be qualitatively seen that the $S$. mutans colony-forming biofilms within a 24-h incubation period appear thicker than those of the 48-h incubation period. From these 
observations, it can be concluded that, in a period of $48 \mathrm{~h}$, the biofilm life cycle has reached the dispersion stage.

According to a theory proposed by the previous researcher, after a biofilm matures within the actual conditions in the human oral cavity, it will disperse as a colony or an individual cell on the surface of the substrate in search of a new substrate, causing biofilm formation to spread. Nutrient limitation within the initial adhesion phase is one of the causes of the dispersion, as the bacteria must find a new location to fulfill its nutritional needs [8]

Quantitatively, the effectiveness of biofilm inhibition on two variations of time for each variation of propolis wax concentration in chewing gum can be calculated and is shown in Table 4 and Fig. 5.

From Table 4 and Figure 5, it can be seen that, after $48 \mathrm{~h}$, the inhibition of cariogenic bacteria activity to form a biofilm due to the interaction with propolis wax chewing gum increased with increasing propolis wax concentration. Thus, it can be concluded that propolis wax chewing gum works effectively in inhibiting the adhesion of bacteria up to the maturation process (attachment-maturation phase) within the first $24 \mathrm{~h}$, which reached $80 \%$ at a concentration of $5 \%$. A recent finding by Soekanto et al., in which casein phosphopeptide-amorphous calcium phosphate (CPP-ACP) with propolis in chewing gum showed different result, decreasing $S$. mutans biofilm mass, was not dependent on increasing the content of propolis nor is it not dose-dependent $[9,10]$. This might occur due to the mixture of CPP-ACP that is a water-like substances while propolis wax is an oil-like substance. Hence, the antibacterial activity was not as strong as in this study.

\section{CONCLUSION}

In summary, after studying the physical characteristics and performing an in vitro analysis of our propolis wax chewing gum formulation, we generated a propolis wax chewing gum using safe materials in accordance with the American FDA, and thus, this gum is safe to consume. The jelutong latex (D. costulata) used as an elastomer in the chewing gum has a glass $\mathrm{Tg}$ at $-22.46^{\circ} \mathrm{C}$ and $33.86^{\circ} \mathrm{C}$, contains volatile components $(14.96 \%)$, polymers $(84.43 \%)$, organic components $(0.36 \%)$, and the inorganic components $(0.25 \%)$. Formulation of sugar-free gum with the addition of propolis wax in the range of $1-5 \%$ generated a chewing gum texture that was almost like that of commercial chewing gums. In sugar-free chewing gum, wax propolis as much as $5 \% \mathrm{w} / \mathrm{w}$ is proved to inhibit $S$. mutans activity in dental plaque biofilm formation, which is
$80 \%$ more effective relative to negative controls with no gum present, and thus, it can be concluded that propolis wax chewing gum works to inhibit the formation of dental caries.

\section{ACKNOWLEDGMENT}

The author would like to thank Universitas Indonesia for their financial support in the form of the Grant of Indexed International Publication of Student Final Project (PITTA)

\section{CONFLICTS OF INTEREST}

There were no conflicts of interest.

\section{REFERENCES}

1. Health Research and Development Agency. Basic Health Research (RISKESDAS) 2013. National Report 2013; 1-384.

2. Forssten SD, Bjorklund M, Ouwehand AC. Streptococcus mutans, caries and simulation models. Nutrients 2010;2:290-8.

3. Alanzi A, Soderling E, Varghese A, Honkala E. Xylitol chewing gums on the market: Do they prevent caries? Oral Health Prev Dent 2016;14:459-66

4. Veloz JJ, Saavedra N, Alvear M, Zambrano T, Barrientos L, Salazar LA, et al. Polyphenol-rich extract from propolis reduces the expression and activity of Streptococcus mutans glucosyltransferases at subinhibitory concentrations. Biomed Res Int 2016;2016:4302706.

5. Gum Base Co. Gum Base. Gum Base Co; 2009. Available from: http://www.gumbase.com/on-line/Home/Confectionery/Products/ GUMBASE.html. [Last retrieved on 2014 Apr 15].

6. Nield-Gehrig J, Willmann DE. Dental Plaque Biofilms. Foundations of Periodontics for the Dental Hygienist; @ 2003 Lippincott Williams and Wilkins. p. 67-73. Available from: http://www.lww.com.

7. Koo H, Rosalen PL, Cury JA, Park YK, Bowen WH. Effects of compounds found in propolis on Streptococcus mutans growth and on glucosyltransferase activity. Antimicrob Agents Chemother 2002; $46: 1302-9$

8. Huang R, Li M, Gregory RL. Bacterial interactions in dental biofilm. Virulence 2011;2:435-44.

9. Soekanto SA, Duhita GC, Bachtiar EW, Sahlan M. The effect of casein phosphopeptide-amorphous calcium phosphate-propolis chewing gum on calcium and phosphate ion levels in caries-free subject's saliva and Streptococcus mutans biofilm formation. Asian J Pharm Clin Res 2017;S:174-6.

10. Hasnamudhia F, Bachtiar EW, Sahlan M, Soekanto SA. The effect of CPP-ACP-propolis chewing gum on calcium and phosphate ion release on caries-active subjects' saliva and the formation of Streptococcus mutans biofilm. J Phys 2017;884:12137. 